\title{
Transformational Leadership through Applied Neuroscience: Transmission Mechanism of the Thinking Process
}

\author{
Solikin M. Juhro*, A. Farid Aulia
}

Bank Indonesia

\begin{tabular}{l}
\hline \\
Keywords: \\
Applied Neuroscience, \\
Leadership Style, \\
Transformational \\
Leadership, Human \\
Resources Management \\
\hline Received \\
07 February 2018 \\
Received in revised form \\
20 July 2018 \\
Accepted \\
21 July 2018 \\
\hline
\end{tabular}

Correspondence:

solikin@bi.go.id

\begin{abstract}
The world has changed as we entered the new situation full of volatility, uncertainty, complexity, and ambiguity. To be able to cope with this situation, an organization has to translate the challenges into a clear vision and action. A leadership style that is agile to adapt with the magnitude and the characteristic of the occurring problem is needed. Transformational leadership is a participative leadership style that is not only able to motivate and drive the organization vertically and horizontally but also always be agile in every circumstance. Thus, the organizational capacity to achieve the shared vision and mission will be encouraged. Applied neuroscience gives an understanding about the activities and mechanism of the brain which improves the required competences of a leader. Therefore, applied neuroscience will help a leader transform the organization. This study shows that applied neuroscience can help a transformational leadership achieve a "physically, emotionally, and mentally safe" state and encourage an organization to transform itself effectively.This study does not only explore a new perspective of transformational leadership issues, but it also provides an important contribution related to applied neuroscience, in particular, mapping transmission mechanism of the brain activities affecting body's reaction, internally (emotions and hormone) and externally (body reaction), which further affect the transformational leadership behaviors.
\end{abstract}

(C)AIMI Journals

Almost a decade since the global financial crisis of 2008/09, the world economic condition has not fully moved toward its normal state. This is reflected, not only by the global economic growth in the last five years which is still below its long-term average, but also the global financial markets that are still overwhelmed by very high uncertainties. The world has changed as we entered the new situation with full of volatility, uncertainty, complexity, and ambiguity, known as VUCA. In this context, the characteristics of problems and challenges continue to 
evolve throughout the history of human civilization. The movement of the future will be more difficult to predict (unpredictable). The root cause of the regulations will be more unclear (unknown). Consequently, the regulation directions which are made by authorities and market participants become more uncertain directing the unpredictable future. Changing is happening fast with new era arises replacing the old one. In addition, the series of crisis occurred last two decades indicates the vulnerability occurring in one country that will be spread into regional and even global crisis with various unpredictable factors.

From the leadership perspective, an organization needs to be prepared and be able to translate the challenges into a clear vision and actions as faces a VUCA world and massive global megatrends (KPMG International, 2014). The world does not need a passive leadership, yet an agile and transformative one who can adapt to the magnitude, orientation, and the characteristic of the occurring problems. Unfortunately, based on World Economy Forum 2015, leadership is the greatest crisis happening the world (Shahid, 2015). Leadership can be either a solution or the root of problems. The survey led by Deloitte from 2014-2015 (Leading the New World of Work Human Capital Trend) to world prominent CEOs showed that the position of leadership is increasingly important, but the gap with current leadership competences is widening at the same time (Deloitte, 2015). The problem faced by the most organization is how to manage the leadership pipeline in the midst of rapid organizational development with the low tendency of engagement. Therefore, a focus on integrated strategic leadership development is needed to identify and develop current and future state of leadership in the dynamic flow of change.

The leadership traits mentioned above are in line with the transformational leadership characteristics. A leadership that not only motivates and drives the followers but also executes the capacity to always be agile in every circumstance. Transformational leadership is a participative leadership style in which the leader and followers work together to achieve the shared vision.

This leadership issue is related to the trend of the shifting orientation from human resources management into brain resources management that has been widely initiated by both of the government and non-government institution, such as Obama's Brain Initiative in the US. The brain, which has more than one hundred billion nerves and hundred trillion connections, encourages neuroscience practitioners to examine the activities and mechanisms of brain cells that affect human's behavior. Neuroscience is defined as a study of the nervous system behind biological processes that occur in the brain when a human thinks or acts. Applied neuroscience research is believed to be an effective solution to help the transformation of people and organization because the brain is the master of control that integrates the entire body system including the main components of heart and gut. The leader is also a master of control within the organization. A leader can control other people's brains by managing their own brains, thus the followers' brains can tune-in with the leader's brain. When the brain of leader and followers are aligned, the leader and followers will synergize effectively to achieve the shared goals (Swart, Chisholm, \& Brown, 2015).

This research recognizes that the problems and potentials complexity in the world cannot be solved only by conventional institutional structures and policies, but should be beyond the conventional wisdom. The exposure about economic leadership needs to be embedded into 
each learning domain in order to create awareness about the importance of innovative leadership and strategic contribution to support sustainable economic growth.

This study is intended to explore issues related to transformational leadership and applied neuroscience as one of the most effective transformational leadership approaches/tools. Specifically, the research questions to be answered through this study are: (i) Why is transformational leadership necessary? (ii) What are the relative advantages of applied neuroscience compared to other approaches? and (iii) How is the transmission mechanism of applied neuroscience in encouraging transformational leadership? This paper will also explain the examples of applied neuroscience implementation in the organizational environment. This study is based on the literature study and focus group discussion (FGD) with experts and leaders. The transformational leadership scope in the context of applied neuroscience is generalizable to both public and private leadership.

The result of the preliminary study concludes that transformational leadership is needed because this style does not only motivate and drive the organization vertically and horizontally but also realizes the capacity of the organization to be agile and adaptive in every circumstance. In this regard, applied neuroscience approach can provide a better understanding of the brain's activities that can help the leader to lead the organizational transformation. In this case, the applied neuroscience through multiple transmission channels can help the transformational leader and followers to achieve physical, emotional, and mental safety as well as encourage the organization to transform effectively. In addition to strive the new perspective of transformational leadership studies, this study provides an important contribution related to applied science, in particular, mapping the transmission mechanism of brain activities that affect body's reaction, internally (emotions and hormone) and externally (body reaction and behavior), which further affect transformational leadership behaviors.

This study consists of four parts. Following this introductory section is the theoretical perspectives of the transformational leadership and related approaches especially applied neuroscience. This section will also address the mechanism of the brain in influencing transformational leadership competences. The third section is the analysis aimed at answering the main research questions in the study: the urgency of transformational leadership; advantages of applied neuroscience; transmission mechanism of applied neuroscience in promoting transformational leadership competences; and some examples of applied neuroscience implementation in the organizational environment. The last part of this study is the conclusion and recommendations for further researches.

\section{Transformational Leadership Definition}

Leadership is a process of influencing others to understand and agree things that need to be done and the ways to do them (Yukl, 2006). Northouse (2007) explains that leadership is a process when a person influences a group of individuals to achieve common goals. Based on the type, leadership can be categorized into two groups, transactional and transformational leadership (Bass, 1990). Transactional leadership is a type of leadership when leaders use reward and punishment to motivate followers. In contrast to transactional leadership, the motivational sources of followers in transformational leadership do not come from external 
reward and punishment but from self-inspiration given by leaders to encourage followers to transform with their internal motivation.

Transformational leadership is a process where leaders and followers help each other to improve the motivation and morality of both parties (Burns, 1978). Yammarino and Bass (1990) argue that transformational leadership is a leadership style when leaders articulate a realistic vision of the organization's future, stimulate followers in an intellectual way, and pay attention to the differences that followers have. Simola, Barling, and Turner (2012) define transformational leadership as an interaction between two parties within an organization with a collective purpose when the leader transforms, motivates, and develops ethical behavior and aspirations of the followers. It can be concluded that transformational leadership is a participative leadership style that improves morality, internal motivation, and performance of the followers by changing followers' mindset and behavior followers as well as organizational effectiveness.

According to Bass (1990), there are four components that form a transformational leadership style, which can be described as follows: (i)idealized/charismatic influence, the leader has a vision and missions that in line with organization, commitment, and consistency in every decision thus the followers follow the leader voluntarily; (ii) inspirational motivation, leader sets high standard and encourages the achievement;(iii) intellectual stimulation, leader pushes the followers to have learning culture and facilitating them to develop it; and (iv) individualized consideration, the leader's ability to understand the differences between each follower and facilitate their development.

\section{Transformational Leadership Competences}

In order to transform the organization, a leader has to have some basic competences which can be grouped into inner, others, and outer cluster, known as The Triple Focus (Goleman \& danSenge, 2014). The clusters show that a transformation has to start from the leader (leading self), then the group of people/followers within the organization (leading people). The last transformation is the organization itself (leading organization).

The inner-focus/leading self is needed so that the leader is aware of the values, feelings, and intuition of himself and understand how to manage them properly. The others-focus/leading people requires leader to be able to read, understand, and manage the relationship with followers. Meanwhile, the outer-focus/leading organization requires leader to be able to understand the strength of the wider system. Leader has to navigate and determine the best-fit intended strategy.

Based on the previous research about the core/mandatory competences that a future leader must possess, there are nine transformational leadership competences. The competences are breakthrough, agility, emotional intelligence (leading self), social intelligence, the ability to influence others, communicating skill (leading people), visionary, problem-solving, and decision making (leading organization).

\section{Transformational Leadership Tools}

A transformation within the organization can be helped with various approaches. The approaches serve to assist the leader creating and accelerating the transformation. Some of the 
transformational leadership approaches and their respective characteristics, can be seen in Table 1.

Table 1

Transformational Leadership Approach Summary

\begin{tabular}{|c|c|c|c|c|c|c|}
\hline \multirow[b]{2}{*}{ No } & \multirow[b]{2}{*}{ Aspects } & \multicolumn{5}{|c|}{ Approaches } \\
\hline & & DRA* & Kubler-Ross' & Jack Welch's & Kotter's & $\begin{array}{c}\text { Applied } \\
\text { Neuroscience }\end{array}$ \\
\hline 1 & Focus & $\begin{array}{l}\text { Trigger to stimulate } \\
\text { transformation }\end{array}$ & $\begin{array}{l}\text { Phases pass through to } \\
\text { transform }\end{array}$ & $\begin{array}{l}\text { Followers } \\
\text { participation }\end{array}$ & $\begin{array}{l}\text { A sense of urgency for } \\
\text { transformation. }\end{array}$ & $\begin{array}{l}\text { Understanding } \\
\text { leader and } \\
\text { followers' brain in } \\
\text { implementing TL }\end{array}$ \\
\hline 2 & $\begin{array}{l}\text { Leader's } \\
\text { role }\end{array}$ & $\begin{array}{l}\text { Show trigger, manage } \\
\text { resistance, manage } \\
\text { reaction of } \\
\text { organizational } \\
\text { transformation }\end{array}$ & $\begin{array}{l}\text { Managing each phases } \\
\text { of transformation }\end{array}$ & $\begin{array}{l}\text { Ask followers to } \\
\text { participate in } \\
\text { achieving vision }\end{array}$ & $\begin{array}{l}\text { Create a sense of } \\
\text { urgency to transform. }\end{array}$ & $\begin{array}{l}\text { Motivate } \\
\text { followers through } \\
\text { an understanding } \\
\text { of the brain's } \\
\text { followers and } \\
\text { leader. }\end{array}$ \\
\hline 3 & Approach & $\begin{array}{l}\text { Managing the risk } \\
\text { happened toward } \\
\text { change triggers. }\end{array}$ & $\begin{array}{l}\text { Through leadership } \\
\text { competences. }\end{array}$ & $\begin{array}{l}\text { Eliminate the } \\
\text { complicated } \\
\text { bureaucracy and } \\
\text { simplify the } \\
\text { vision. }\end{array}$ & $\begin{array}{l}\text { Explain the } \\
\text { consequences that can } \\
\text { be generated if the } \\
\text { transformation didn't } \\
\text { happened }\end{array}$ & $\begin{array}{l}\text { Understanding } \\
\text { reward and threat } \\
\text { to motivate } \\
\text { followers }\end{array}$ \\
\hline 4 & $\begin{array}{l}\text { Leader's } \\
\text { competences }\end{array}$ & $\begin{array}{l}\text { Not improved } \\
\text { specifically. }\end{array}$ & $\begin{array}{l}\text { Not improved } \\
\text { specifically. }\end{array}$ & $\begin{array}{l}\text { Not improved } \\
\text { specifically. }\end{array}$ & $\begin{array}{l}\text { Not improved } \\
\text { specifically. }\end{array}$ & $\begin{array}{l}\text { Improved with } \\
\text { applied } \\
\text { neuroscience. }\end{array}$ \\
\hline 5 & Steps & $\begin{array}{l}\text { 1. The transformation } \\
\text { started with a } \\
\text { trigger (driving } \\
\text { force). } \\
\text { 2. There will be } \\
\text { resistance of } \\
\text { transforming } \\
\text { organizational, } \\
\text { policies or status } \\
\text { quo position } \\
\text { (resisting force). } \\
\text { 3. There will be } \\
\text { reaction from } \\
\text { running } \\
\text { transformation } \\
\text { (attracting forces). }\end{array}$ & $\begin{array}{l}\text { Emphasizes the stages } \\
\text { that occur when } \\
\text { external change occurs } \\
\text { and ask for } \\
\text { transformation } \\
\text { 1. Shock. } \\
\text { 2. Denial. } \\
\text { 3. Frustration and } \\
\text { Anger. } \\
\text { 4. Depression. } \\
\text { 5. Experiment and } \\
\text { Decision. } \\
\text { 6. Acceptance and } \\
\text { Integration. } \\
\text { 7. Ready to transform. }\end{array}$ & $\begin{array}{l}\text { Jack Welch } \\
\text { implemented } 25 \\
\text { things that can } \\
\text { ring organizations } \\
\text { to transform, } \\
\text { including } \\
\text { articulating vision } \\
\text { with simplicity, } \\
\text { giving freedom to } \\
\text { work, creating } \\
\text { learning culture, } \\
\text { focusing on } \\
\text { innovation, etc. }\end{array}$ & $\begin{array}{l}\text { 1. Sense of urgency. } \\
\text { 2. Creating guiding } \\
\text { coalition. } \\
\text { 3. Creating a vision } \\
\text { and strategy. } \\
\text { 4. Communicating } \\
\text { vision changes. } \\
\text { 5. Wide-spreading } \\
\text { action. } \\
\text { 6. Short-term victory } \\
\text { 7. Consolidating } \\
\text { progress and creating } \\
\text { change. } \\
\text { 8. A new approach in } \\
\text { organizational culture. }\end{array}$ & $\begin{array}{l}\text { Applied } \\
\text { neuroscience } \\
\text { provides an } \\
\text { understanding of } \\
\text { how to drive } \\
\text { followers without } \\
\text { coercion and } \\
\text { improves } \\
\text { transformational } \\
\text { leadership } \\
\text { competences. }\end{array}$ \\
\hline
\end{tabular}

*Note: DRA (Driving, Resisting, and Attracting Forces)

\section{Applied Neuroscience and the Perspective Theory of the Brain}

From a scientific point of view, neuroscience is a study of the nervous system. Neuroscience studies the structure of the human nerves, how they form, how they work, the possible malfunctions of the brain, and how they can change. In general, the views on the brain can be differentiated into brain-based and thinking-based. Brain-based provides an understanding of the anatomical structure of the brain, while thinking-based provides the understanding of brain functions and thought processes that occur in the brain. In accordance with its relevance, the exposure to this section will focus on thinking-based theory.

One of the leading theories that fall within a thinking-based theory is the split brain theory. This theory became known when Roger W. Sperry was awarded a Nobel Prize in 1981 for his work with "split-brain" patients. Sperry reveals that the human brain consists of two parts (hemispheres), the right hemisphere and the left hemisphere, which are connected by a bridge called the corpus callosum. Sperry also reveals that the right hemisphere and the left hemisphere have different functions. The left hemisphere is related to the ability to write, speak, and count, while the right hemisphere has functions related to spatial ability, 
construction, ideation, creativity, simple language skills, nonverbal skills, and comprehension skills.

Sperry's theories developed into a theory of the human thought process. Some applied neuroscience experts such as Ned Herrmann, Steve Peters, and Waytz and Mason, have developed the thinking-based brain modelling as follows in Table 2.

Table2

Brain Modeling

\begin{tabular}{|c|c|c|c|}
\hline & Model & Areas & Description \\
\hline \multirow{4}{*}{ Ned Herrmann } & \multirow{4}{*}{$\begin{array}{l}\text { The Whole } \\
\text { Brain Thinking } \\
\text { System }\end{array}$} & Blue area (goal driven) & Logical, analytical, quantitative, factual \\
\hline & & Yellow area (vision driven) & Holistic, intuitive, integration, synthesis \\
\hline & & Green area (task driven) & Organization, sequential, planned, detailed \\
\hline & & Red area (people driven) & Interpersonal, feeling, kinesthetic, emotional \\
\hline \multirow{4}{*}{ Steve Peters } & \multirow{4}{*}{$\begin{array}{l}\text { Mind } \\
\text { Management } \\
\text { Model }\end{array}$} & Human Brain & Cognitive function \\
\hline & & Chimp Brain & Affective function \\
\hline & & Computer Brain & Habitual function \\
\hline & & Physical Brain & Overall brain capability \\
\hline \multirow{4}{*}{$\begin{array}{l}\text { Waytzand } \\
\text { Mason }^{i}\end{array}$} & \multirow{4}{*}{$\begin{array}{l}\text { Brain network } \\
\text { at work }\end{array}$} & Default network & Introspection and imagination in time, place and reality \\
\hline & & Reward network & Response to pleasure (pleasure) \\
\hline & & Affect network & Central role in emotion \\
\hline & & Control network & Understand the consequences, stimulate control and selective attention \\
\hline
\end{tabular}

From the models, brain function in general can be divided into rational function and emotional function. The rational function is set in the human brain (also called the prefrontal cortex) while the emotional function is governed by the chimp brain (limbic system). Human brain and chimp brain have different personalities, way of thinking, and how to work. Not that human brain works purely without the influence of chimp brain, and vice versa. However, when the brain acts rationally, the emotions will be suppressed, and vice versa. A good leader should know the right moment to activate the human brain and/or chimp brain. Although basically any rational decision cannot escape the emotion, the leader must be able to suppress the emotional brain and put forward the rational brain so that the decisions are taken more precisely and accountable.

Applied neuroscience is an approach to understand the brain activity of a person when he makes the decision to perform a behavior. The leader is expected to make decisions, establish the relationship, and accommodate the changes within organization effectively. ${ }^{\mathrm{ii}}$ In general, the discussion about brain function and activity will refer to Peters' Mind Management Model (2012) which summarized in table 3.

Table 3

Mind Management Model by Steve Peters (2012)

\begin{tabular}{|c|c|c|c|c|}
\hline No & Function & Area/part & Challenges & Mitigation \\
\hline \multirow{2}{*}{1} & \multirow{2}{*}{ Human Brain (executive function) } & \multirow{2}{*}{ Prefrontal Cortex/PFC } & Unconscious Bias & SEEDS Model of Bias \\
\hline & & & Amygdala Hijack & Affect Labelling \\
\hline \multirow[t]{2}{*}{2} & \multirow{2}{*}{ Chimp Brain (emotional function) } & \multirow{2}{*}{ Limbic System } & \multirow{2}{*}{$\begin{array}{l}\text { Threat \& reward } \\
\text { stimulus }\end{array}$} & SCARF Model \\
\hline & & & & Emotional Driver Model \\
\hline 3 & Computer Brain (value and belief function) & Parietal Lobe & Fixed Mindset & Growth Mindset $^{\mathrm{iii}}$ \\
\hline 4 & $\begin{array}{l}\text { Physical Brain (neuroplasticity, hormone, } \\
\text { and other physical function of the brain }\end{array}$ & $\begin{array}{l}\text { The Physical Brain (its } \\
\text { neurons, synaptic and } \\
\text { chemical processes) }\end{array}$ & Stress & Brain foods and exercise \\
\hline
\end{tabular}

SEEDS: Similarity, Experience, Expedience, Distance, and Safety (in Rock \& Ringleb, 2013)

SCARF: Status, Certainty, Autonomy, Relatedness, and Fairness (in Rock \& Ringleb, 2013) 
According to the previous studies (Sinek, 2015; Swart et al., 2015), the fulfillment of transformational leadership competences can be achieved with applied neuroscience interventions. Some examples of the well-known applied neuroscience interventions, such as relaxation, physical activity and brain, affecting labeling, mindfulness, interaction, the understanding of communication preferences, SCARF regulation, chunking strategies, AHA moment achievement, and bias mitigation can be used to manage the emotions. Emotions that are well managed will trigger the release of hormones that have a positive impact on the leadership behaviors.

\section{The Urgency of Transformational Leadership}

There are many terms, which have been studied and practiced in theory and practice of conventional management, representing leadership styles such as autocratic, democratic, delegated, bureaucratic, laissez faire, authoritarian, spiritual, situational, etc. Although there are basic similar characteristics of each style in general, the leadership styles will continue to develop faced the challenges of the era. Bass (1990) states that there are two styles of leadership: transactional leadership and transformational leadership. Transformational leadership is considered the most appropriate and effective style to be applied in the VUCA era. The urgency of transformational leadership, as well as its relative superiority compared to another one, can be seen in the Table 4 .

Table 4

Transactional vs. Transformational Leadership

\begin{tabular}{|c|c|c|}
\hline No & Transactional leadership style & Transformational leadership style \\
\hline 1 & Motivating followers by fulfilling their personal desires. & $\begin{array}{l}\text { Motivating followers by encouraging them to put the organization's } \\
\text { interests above group's interests. }\end{array}$ \\
\hline 2 & $\begin{array}{l}\text { Followers achieve the goals with rewards and } \\
\text { punishments. }\end{array}$ & $\begin{array}{l}\text { Followers undergo self-transformation through developing idealism and } \\
\text { values in achieving goals. }\end{array}$ \\
\hline 3 & The responsive actions tend to be stiff. & The proactive actions tends to be adaptive to changes. \\
\hline 4 & Focus on current situations. & Have long-term goals. \\
\hline 5 & Can be used in stable organization properly. & Can be used in organization that experiencing turbulence properly. \\
\hline 6 & Works in an established organizational culture. & Works to change organizational culture by proposing new ideas. \\
\hline 7 & Does not accommodate creativity and innovation. & Proper for organization that requires creativity and innovation. \\
\hline 8 & Decision-making is in bureaucratic style. & $\begin{array}{l}\text { Decision making tends to be more practical because it relies on the } \\
\text { agility and personal influence of the leader. }\end{array}$ \\
\hline 9 & $\begin{array}{l}\text { Applied neuroscience's perspective: employees will never } \\
\text { be satisfied with the rewards thus, the rewards should } \\
\text { always be increased. }\end{array}$ & $\begin{array}{l}\text { Applied neuroscience's perspective: } \\
\text { Employees understand the reason behind transformation this the output } \\
\text { is sustainable transformed so that the transformation is sustainable. }\end{array}$ \\
\hline
\end{tabular}

Based on the summary in Table 4, an understanding can be drawn that transactional leadership is no longer effective to be implemented in the VUCA era. Organizations need a flexible and adaptive leader, which are the traits of transformational leaders. Bureaucracy and rules that are applied to the transactional leadership implementation tend to be too rigid to the extent that it cannot accommodate creativity, innovation, and the need of new visions. Transformational leadership is a leadership style that is able to accommodate aspects that are lacking in transactional leadership. From the previous description can also be seen that the 
competences of transformational leadership are complete, which also include some competences of conventional leadership styles. As a future leadership style, transformational leadership is ultimately believed to transform the paradigm and values within the organization to achieve the vision and mission optimally.

\section{Matrix Analysis of Transformational Leadership Competences and Tools}

Based on the literature review, there are at least five approaches that can be used to encourage the transformational leadership implementation, which are Driving Force - Resisting Force Attracting Force (DRA), Kubler-Ross' Change Curve, Jack Welch's 25 Ways of Transformation, Kotter's eight steps of leading change, and transformation leadership based on applied neuroscience. The comparative ability of approaches to target the transformational leadership competences is presented in Table 5.

Table 5

The Advantages of Applied Neuroscience

\begin{tabular}{|c|c|c|c|c|c|c|c|c|c|c|c|c|c|}
\hline \multirow[b]{2}{*}{ No } & \multirow[b]{2}{*}{ Approach } & \multicolumn{12}{|c|}{ Transformational Leadership and other Leadership Competences } \\
\hline & & 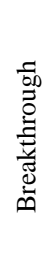 & 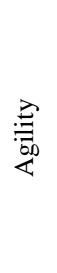 & 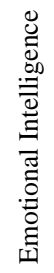 & 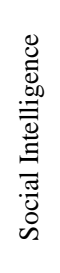 & 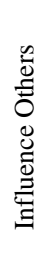 & 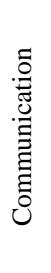 & 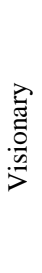 & 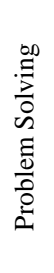 & 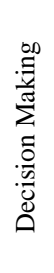 & 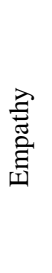 & $\begin{array}{l}\text { 害 } \\
\text { 营 } \\
\text { 竞 }\end{array}$ & 营 \\
\hline 1 & DRA & & & & & $\checkmark$ & $\checkmark$ & $\checkmark$ & & & & & \\
\hline 2 & Kubler-Ross' & $\checkmark$ & $\checkmark$ & $\checkmark$ & & & $\checkmark$ & & $\checkmark$ & $\checkmark$ & & & \\
\hline 3 & Jack Welch's & $\checkmark$ & $\checkmark$ & & & & $\checkmark$ & $\checkmark$ & & & & & $\checkmark$ \\
\hline 4 & Kotter's & & & & & $\checkmark$ & $\checkmark$ & $\checkmark$ & & & & & \\
\hline 5 & Applied Neuroscience & $\checkmark$ & $\checkmark$ & $\checkmark$ & $\checkmark$ & $\checkmark$ & $\checkmark$ & $\checkmark$ & $\checkmark$ & $\checkmark$ & $\checkmark$ & $\checkmark$ & $\checkmark$ \\
\hline
\end{tabular}

As indicated in Table 5, the approach of applied neuroscience targets more aspects of transformational leadership competences, breakthrough, agility, emotional intelligence, social intelligence, the ability to influence others, communicating skill, visionary, problem-solving and decision making, as well as several aspects of other leadership competences such as empathy, spirituality, coaching, counseling, mentoring and vibrant leadership. Meanwhile, the approach proposed by Kubler-Ross and Jack Welch are at the second and third position relatively in targeting transformational leadership aspects. Thus, the applied neuroscience approach is relatively superior to other approaches.

\section{The Transmission Mechanism of Thinking Process}

As discussed in the previous section about the nine transformational leadership competences, this section will discuss the advantages and mechanism of how applied neuroscience works in improving the competences. If the intervention of applied neuroscience can target transformational leadership competences well, the ultimate goals of the organizational effectiveness can be maximized. The main issue that arise at the operational level is how many ways or transmission paths the way applied neuroscience can target these competences. This is 
related to how the brain works to affect the body's reaction, both internally (emotionally and hormonally) and externally (reaction or action) which affect leadership behavior.

As previously mentioned, the fulfillment of transformational leadership competences (intermediate goals) can be achieved with applied neuroscience interventions, such as relaxation, physical and brain exercise, affecting labeling, mindfulness, managing interaction, understanding of communication preferences, SCARF regulation, chunking strategies, AHA moment, and bias mitigation. The intervention is done to manage the released emotions. The well-managed emotions will trigger the releasing of positive hormones which impact leader's reaction and leadership behaviors.

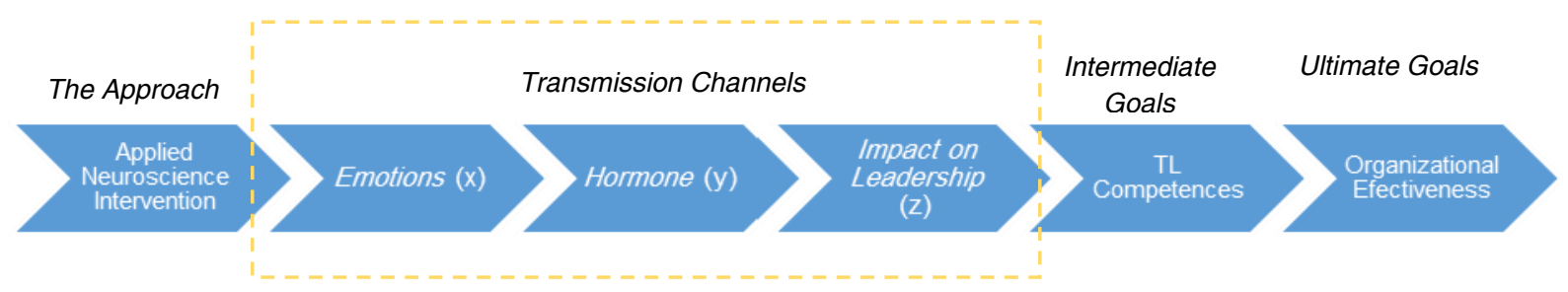

Figure 1. The transmission mechanism of applied neuroscience intervention in transformational leadership

Where:

$\mathrm{x}$ : Basic emotion spectrum (Swart et al., 2015)

y: Hormone (Sinek, 2015)

z: Impact on leadership

\section{Facilitating Breakthrough}

The world that is filled with change demands a leader to always innovate in order for the organization to survive. Innovation can only happen if the leader has the competency to make a breakthrough and has the ability to facilitate the followers making a breakthrough. Applied neuroscience helps the leader to encourage breakthrough.

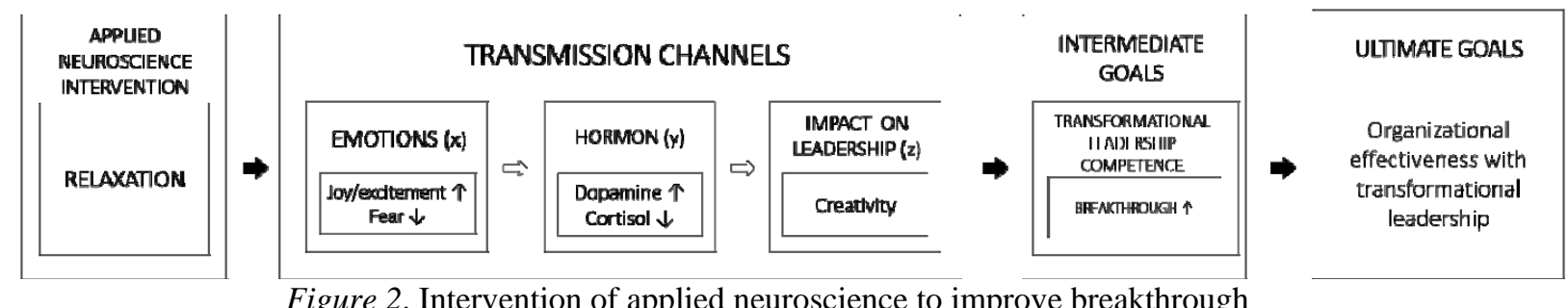

Relaxation techniques such as surround yourself with the blue color and daydreaming can help the leader to create positive emotion (joy/excitement) and lowering the negative emotion (fear). The positive emotion will trigger the brain to produce dopamine and lower the cortisol in the body. ${ }^{\text {iv }}$ This will encourage the creativity and the ability to facilitating change. Both capabilities are the indications that a leader has been able to make a breakthrough. 


\section{Improving Agility}

Leaders constantly face new situations that require them to always be adaptive. This ability requires a leader to have agility in both attitude, learning, and self-development. Applied neuroscience provides an understanding about structured and effective ways for a leader to improve his agility.

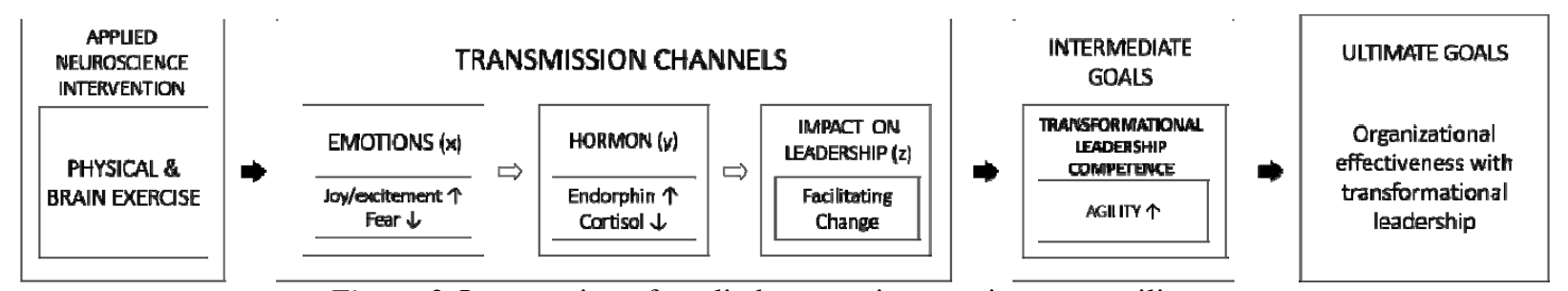

Figure 3. Intervention of applied neuroscience to improve agility

Physical activity, such as exercise and dancing can make a person feel the joy/excitement that affects the production of the endorphin and also the decreased levels of the cortisol in the body. ${ }^{v}$ Changes in both hormones cause a leader to have an ability to facilitating change. This ability will directly address the agility competence of a transformational leader.

\section{Managing Emotional Intelligence}

Emotional intelligence is an ability to be aware of emotions, to regulate emotions for particular purposes, and to have empathy for others. A leader who does not understand how emotion works tend to be reactive in facing problems and emotional in making decisions. With the understanding of how the brain works, a leader will be aware when the chimp brain (related to the emotional function) is active. Therefore, the leader will be able to suppress the emotion and have a clearer and more rational decision.

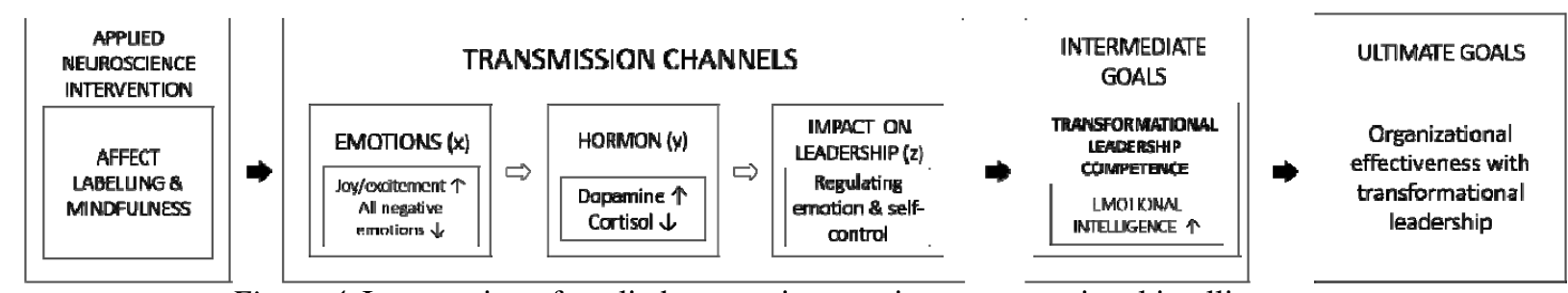

Figure 4. Intervention of applied neuroscience to improve emotional intelligence

The affect labeling (the activity of identifying perceived emotions) and mindfulness meditation are some examples of applied neuroscience interventions that can be done to help a leader improving his emotional intelligence. Both of these activities can neutralize emotion by increasing positive emotion (joy) and decreasing negative emotions (fear, anger, shame, disgust, and sad). Emotional changes will affect the production of dopamine and the decrease of cortisol, so leaders have the ability to regulate emotion and have self-control. Both of these things are indicators that a leader has a good emotional intelligence. 


\section{Establishing Social Intelligence}

Social intelligence has an essential role in leadership process. By understanding the situation and activating the right part of the brain to face each situation, the leader will be able to collaborate and achieve organizational goals effectively.

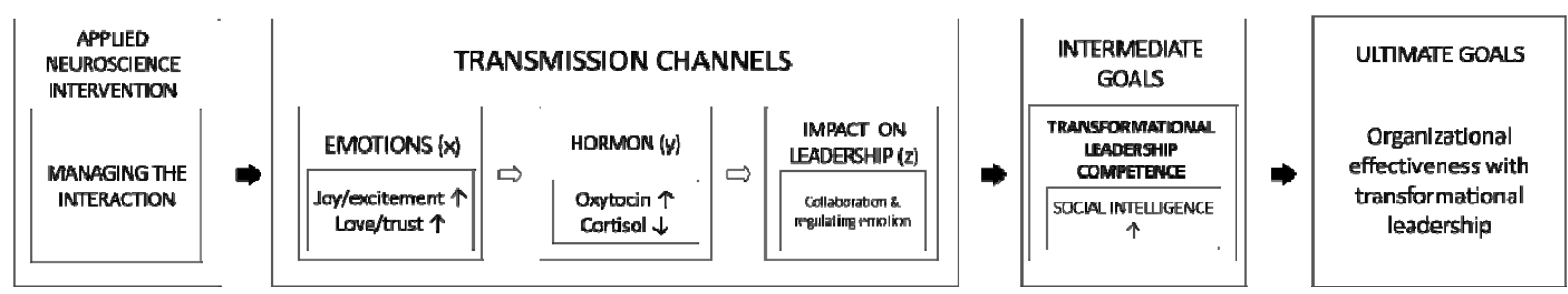

Figure 5. Intervention of applied neuroscience to improve social intelligence

Social intelligence can be enhanced by interacting with other people, for example by gathering or simply chit-chatting with colleagues. Positive interaction with other people causes the brain feel happy emotions (love/trust) with colleagues. These positive emotions trigger the production of oxytocin and stop the releasing of cortisol. ${ }^{\mathrm{vi}}$ This will affect the leader's ability to collaborate and regulate the emotions. These abilities are indicators that the leader has good emotional intelligence. The leader also has to know how to stand against the followers' SCARF (status, certainty, autonomy, relatedness, and fairness). By knowing that a stimulus is considered as threat or reward by the follower, the leader will be able to manage their emotion well. Then, the result of the situation is effective and acceptable.

\section{Developing Communication Skill}

Communication is a process of two or more individuals receiving the messages, information, knowledge, and others. It plays an important role of leader and followers relationship. Good communication occurs when the individual fully understands the information in absented of mental blocks. The mental block occurs when the brain deletes the unwanted information, called deletion, thus the information received will be only partially accepted.

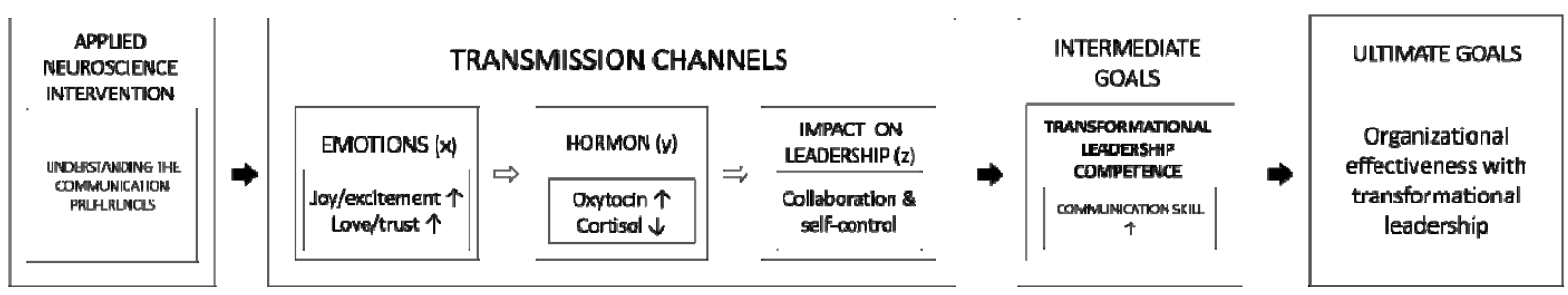

Figure 6. Intervention of applied neuroscience to improve communication skill

The leader has to understand the characteristics and preferences of the followers' communication. Each type of communication style has its own ways to deliver and receive messages. By using follower's communication preferences, the leader will be affected by positive emotion (joy/excitement and love/trust) that triggers oxytocin and decrease cortisol. This makes the leader possess a good self-control and collaboration skill. Thus, the leader will have good communication skills. 


\section{Improving Influencing Skill}

The ability to influence others is one of the essential components of the leadership process. The leader has to be able to make the followers carry out the goals together with their internal motivations. By understanding the applied neuroscience, leader will understand how to get followers' emotion so that they are willing to do the shared goals enthusiastically.

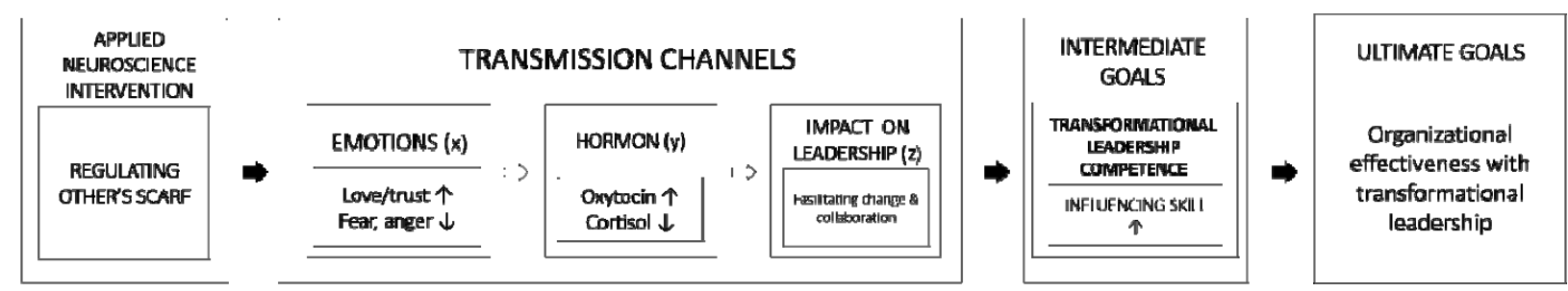

Figure 7. Intervention of applied neuroscience to improve influencing skill

In order to have the ability to influence others, the leader has to manage the other people SCARF position by bringing the position closer to rewards. The ability to manage others position closer to reward will affect to leader's emotion to feel love and trust, which respectively decrease the negative emotions, fear and anger. These emotional changes will trigger the brain to produce oxytocin and lower the cortisol that help the leader in facilitating change and collaborating with others. The impact is that the leader has a good self-control and collaboration sense. Thus, a leader will have good influencing skill.

\section{Expanding Vision}

The leader has to be able to translate the long-term vision into short and mid-term strategies explicitly. Then, the brain will become more focused and excited toward the vision consciously and unconsciously. The focus to achieve the vision will stimulate the body to produce the endorphin. Chunking the vision into short and mid-term strategies will reduce the fear of uncertainty future. Then, the cortisol level will decrease. Short-term winnings, which decreases the pressure, are seen as rewards increasing the dopamine level. It will help the leader in making the decision, facilitating the change and collaborating, thus encouraging the visionary skill.

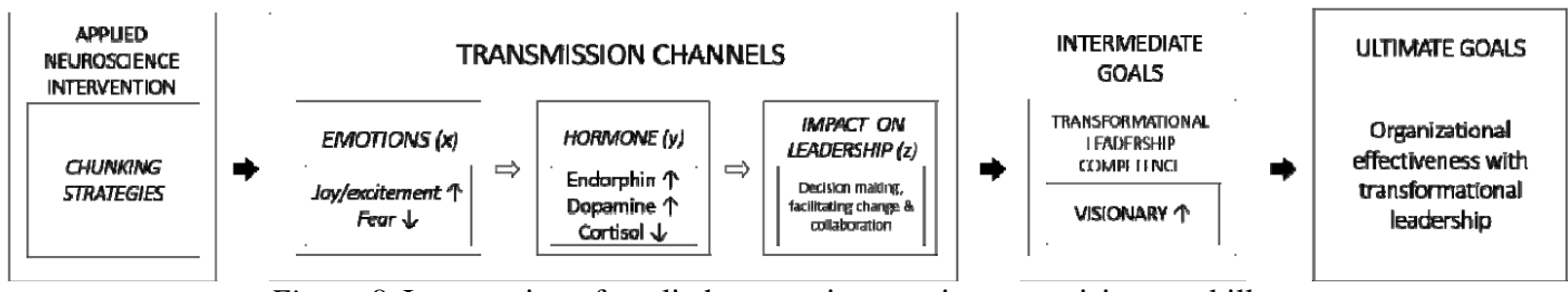

Figure 8. Intervention of applied neuroscience to improve visionary skill

If the leader does not share the vision to the followers, then the followers do not have the responsibility to perform the mandated work. The followers will argue that the work and its success belong to the leader. They are only a worker who needs to meet the targets set by the leader. The transformational leadership requires the leader to drive the internal motivation of the followers by creating a shared vision that guides the organization's entities to achieve common goals with same paces. 


\section{Sharpening Problem Solving}

Problem solving is the act of finding the solution which was unthinkable at first place. It explains the logical reasoning behind the AHA moments (eureka moment). The AHA moment happens when a person does unrelated things to the faced problem. It happens when the brain feels relaxed such as in taking a bath, cooking, fishing and other activities.

The first step in problem solving is the leader collects the data and information of the problems as much as possible. Then, the leader tries to be relaxed thus our brain is in alpha state by forgetting the problems for a moment. When the brain is relaxed, the PFC makes the connection from the collected information. Achieving the AHA moment will enhance the positive emotions and reduce negative emotions. Thus, the dopamine level increases and the cortisol level decreases. This makes the creativity and decision-making ability increase. It then increases the problem solving skill.

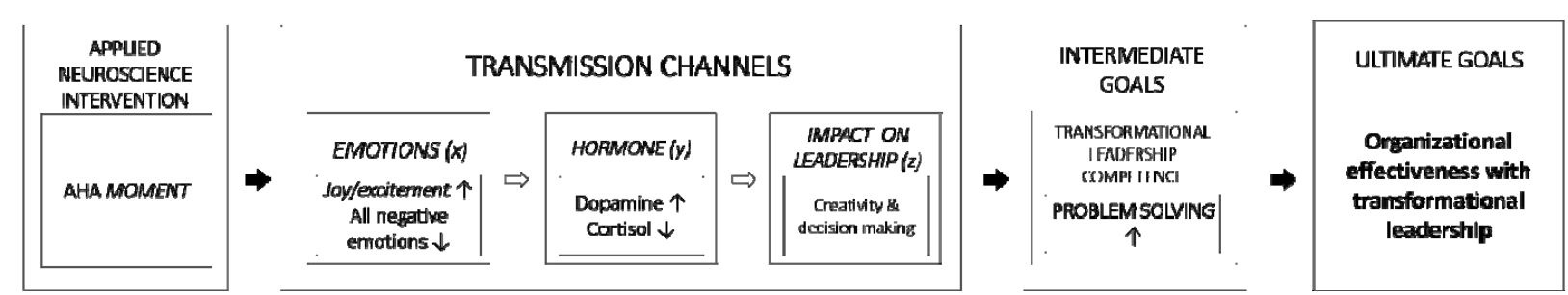

Figure 9. Intervention of applied neuroscience to improve problem solving

\section{Improving Decision Making Skill}

The ability to identify the values and preferences is needed to determine the choice from alternatives. The good decisions are a result of calculations, probabilities of success, effectiveness, and conformity with the objectives and values held. The leader sometimes makes some biases that affect the organization in the process of making decisions. Bias, in decision making context, is divided into SEEDS Model of Bias by David Rock. The bias can be minimized by the rational considerations.

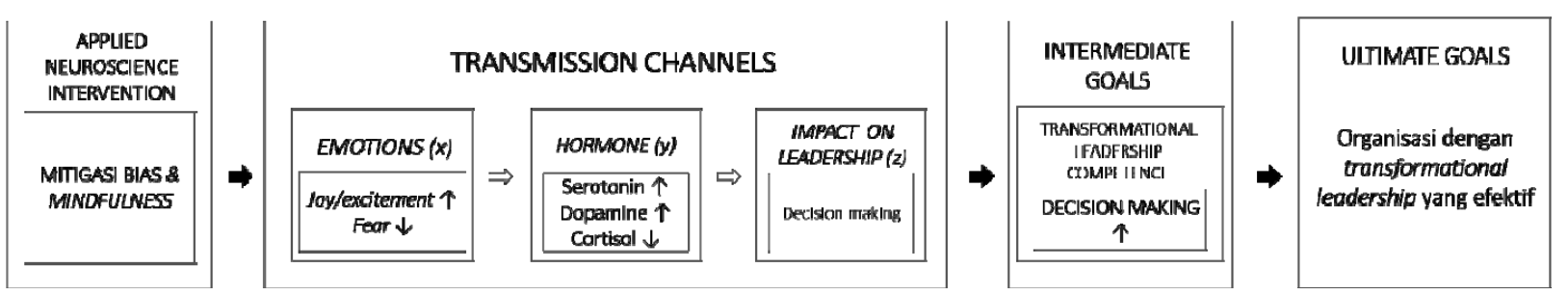

Figure 10. Intervention of applied neuroscience to improve decision making

The proper decision making with minimum bias results in the effectiveness of decision itself. Besides mitigating biases, the ability to make decisions can be enhanced by using mindfulness meditation, which only takes five minutes. Mindfulness meditation is based on an understanding of applied neuroscience regarding activation of the PFC and deactivation of the limbic system.

The bias mitigation and mindfulness meditation enhance positive emotions (joy/excitement), then encourage the brain to produce dopamine and serotonin. ${ }^{\text {vii }}$ By mitigating bias and taking mindfulness meditation, the negative emotions (fear) as well as the cortisol will 
also be lowered. This situation will impact creativity and decision making skill. It increases decision making skill. The transmission mechanism of applied neuroscience intervention in targeting any transformational leadership competence is summarized in Figure 11.

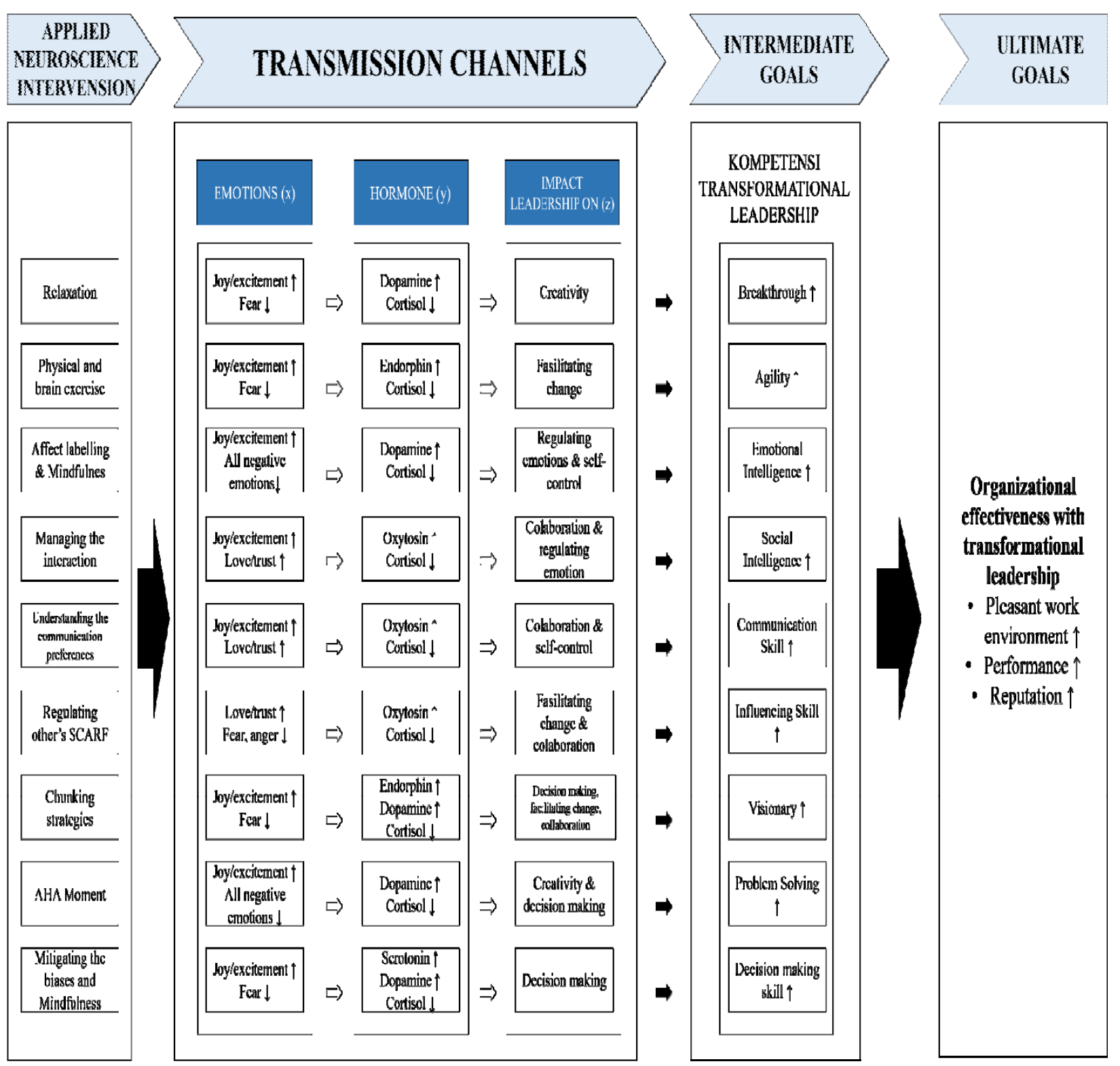

Figure 11. Transmission channels of applied neuroscience intervention summary

\section{The Application of Applied Neuroscience in Organization}

The following sections explore some examples of applications of applied neuroscience in an organizational environment:

\section{Recruitment and Selection}

In order for the individual and organizational performance to be effective, a job must be provided in accordance with the individual's passion and interest. The neurotransmitters that 
secrete hormones of happiness will make individual exert all of his energy to do the work given. This internal motivation that caused by the concern for the work (free-will) will encourage individuals to perform effectively. When the individuals work with their free-will, then in addition to the effectiveness of organizational performance, their self-actualization will be achieved.

\section{Performance Review}

Human is naturally afraid of uncertainty and change. Uncertainty and change that occur at the performance review are seen as a threat. In performing performance review, leader must be able to lower the fairness and status threat. The leader is required to reduce the tension and manage the emotion of followers when performance review takes place. The absence of threat will reduce the opportunities for mental block and defense mechanism to occur so the communication will be more effective. In two-way interaction, followers' demotivation will be less likely to occur.

\section{Education and Training}

The development of education and training curriculum can be understood by the way the brain responds to certain activities. According to applied neuroscience, aerobic exercise is an effective way to improve engagement and stickiness of skill learned, increase motivation, and eliminate stress. Exercise naturally increases hormones such as serotonin, dopamine, and endorphins, which are energetic and happy hormones which can reduce depression and anxiety. In addition to aerobic exercise, learning can be done with the gamification system. Gamification helps to create happiness and decrease anxiety that can produce dopamine and oxytocin, also reduce cortisol. This affects the stickiness of the skill learned, interaction ability, and decreased stress.

\section{Remuneration}

Remuneration can be provided through financial and non-financial rewards. However, applied neuroscience research explains that financial factor is not the main factor that keeps followers loyal and performs. Non-financial factors play a more important role in motivating followers. Non-financial rewards can be provided by bringing the SCARF position towards the reward position. Both of the financial and non-financial rewards will make the brain produce serotonin and oxytocin hormones in which make followers work more effectively.

\section{Policy Making}

In the act of good-quality policy making, a leader can apply the principles of applied neuroscience as well as transformational leadership competences. In this regard, applied neuroscience can help the leader to have the situation under his control, such as by providing an understanding of the importance of feeling relaxed in an attempt to gain insight. Applied neuroscience also provides the understanding that a leader has to be ready and open to any possibility. In a relaxed and full-fledged state, the leader will be able to manage the threat as well as the reward effectively. This state will contribute positively to the development of outer 
(leading organization) transformational leadership competences, such as visionary, problemsolving, and decision making.

The leader's ability to create a vision is needed in formulating a good-quality policy. Applied neuroscience provides an understanding that policies aimed at a great vision must be broken down into smaller strategic plans. This will lead to short-term outcomes that will be perceived as rewards. The perceived rewards cause the brain producing dopamine associated with the memory and the motivation. A leader should be able to avoid biases that can occur when formulating policies. Biases can be mitigated by the SEEDS Model of Bias that is introduced by David Rock. A leader also has to be able to avoid the amygdala hijack that can be mitigated by doing the affect labeling.

\section{Organizational Culture Development}

Applied neuroscience provides an understanding that change cannot be done with the initial stimulus in the form of a threat. The threat will activate the fight-or-flight system that located on the limbic system that will make followers more resistant to the development of new behaviors. Tompson (2015) suggested that an initial stimulus in the form of tailored messages is more effective in activating the ventral medial prefrontal cortex (vmPFC) that determines whether a person is willing to change behavior. Behavior that has been formed must be done consistently. It aims to strengthen the synapses that associated with the behavioral habituation. Once the behavior becomes a habit, this should be celebrated with a reward to produce dopamine, thus the followers will be motivated to act the new habit continuously. The thing to be noted is the reward given should not be a monetary reward.

\section{Anticipation of the Future Challenges}

In the anticipation of problems in VUCA/unknown-unknown word, a leader needs to be agile and adaptive. The leader should be able to see potential future problems. A wise leader will be aware not to use the old way of thinking. The key to coping with the change is learning and using growth mindset. A leader must be willing to learn and see the problem from different perspectives. A leader also has to be able to formulate a vision and various strategies to deal with the unknown- problem. The leader is required to be able to drive the internal motivation of followers to accept and execute the new strategies effectively. Strategies run by every entity of the organization will be inclusive and sustainable.

\section{Conclusion}

Based on this study, it can be drawn some conclusions as follows. First, the transformational leadership is needed because this leadership style does not only motivate and move the organization vertically and horizontally but also realizes the organizational capacity to be agile and adaptive in the dynamics of the world. In this regards, to face the challenges in VUCA era, organizations need the agile and adaptive leaders. A leader must learn continuously and renew the vision as well as organizational strategies in order to be adaptive with the world that changes rapidly. Thus, as a future leadership style, transformational leadership is ultimately believed to transform the paradigm and values within the organization in achieving its vision and mission optimally. 
Second, the applied neuroscience approach is relatively superior compared to other approaches in encouraging transformational leadership competences. It can provide a better understanding of brain's activity that helps a leader to lead the organizational transformation. Compared to other approaches, applied neuroscience addresses broader transformational leadership competences, such as breakthrough, agility, emotional intelligence, social intelligence, influencing ability, communication skill, visionary, problem-solving, decision making, and the other competences such as empathy, spirituality, vibrant, coaching, counseling, and mentoring.

Next, the applied neuroscience, through some channels, can help transformational leaders and followers to achieve physical, emotional, and mental safety to transform effectively. In this case, the achievement of transformational leadership competences, as intermediate goals, can be achieved with the intervention of applied neuroscience, such as relaxation, physical and brain exercise, affect labelling, mindfulness, managing the interaction, understanding the communication preferences, regulating other's SCARF, chunking strategies, AHA moment and mitigating bias, to control the releasing emotions. A well-managed emotion will trigger the release of positive hormones that have a good impact on leader' reaction or behaviors.

Last but not least, the applied neuroscience shows the appropriateness of a reliable approach not only from scientific perspectives but also from leadership practices. The examples of applied neuroscience in work environment in this study are recruitment and selection, training, performance review, remuneration, policy making, organizational-culture development, and future anticipation. An organization will be ready to transform if it is led by a transformational leader, who has transformed the followers within the organization. In this regard, an understanding of applied neuroscience can help a leader creating a transformation of himself, the followers and the organization.

\section{Recommendation}

To implement organizational vision and mission effectively in the midst of the future's new challenges, transformational leadership needs to be done by all levels of organizational leaders, both within the small scope (corporate leaders) as well as the broad scope (regional and national leaders). An organization will be ready to transform if it is led by a leader who has been transformed and there are members who have also been transformed in it. In this regard, an understanding of applied neuroscience can help a leader transforming himself, his followers, as well as the organization. The understanding of applied neuroscience can be done by utilizing the natural workings of the four parts of the brain: the human brain, the chimp brain, the computer brain, and the physical brain. Therefore, through various structured and gradual trainings, leaders in every organizational layer are recommended to maximize the performance of the four parts of the brain.

Despite the claim that this study analytically makes an important contribution to science application in a leadership context, particularly about the mapping of the transmission mechanism that influences the leadership behavior, the author has to validate the claims. This is to ensure the compatibility, not only theoretical aspects and practice in organizations, but also the image of the physical brain when it works. Therefore, further steps are needed, especially the validation results through the medical brain-based test and executive brain 
assessment. In this case, the authors are deepening this study through some supportive tests, which are expected to accomplish various studies related to applied neuroscience field.

\section{References}

Bass, B. M. (1990). From transactional to transformational leadership: Learning to share the vision. Organizational Dynamics, 18(3), 19-31.

Burns, J. M. (1978). Leadership. New York: Harper and Row.

Deloitte. (2015). Leading in the new world of work human capital trends 2015. Retrieved from https://www2.deloitte.com/content/dam/Deloitte/sg/Documents/human-capital/sea-hc-human-capital-trends-2015-southeastasia-edition-noexp.pdf

Dweck, C. (2006). Mindset: The new psychology of success. New York: Random House.

Goleman, D., \& danSenge, P. (2014). The triple focus: A new approach to education. Florence: More Than Sound Productions.

Koteinkkov, V. (2007). 25 Lessons from jack welch creating the world's most competitive enterprise [PowerPoint slides]. Retrieved from https://www.google.com/search?q=25+lessons+from+jack+welch+ppt\&rlz=1C1CHBD_enID734ID734\&oq $=25+$ jack+wel\&aqs chrome.2.69i57j0l3.8351j0j4\&sourceid=chrome\&ie=UTF-8.

Kourdi, J. (2015). The big 100: The 100 business tools you need to success. UK: Hachette.

KPMG International. (2014). Future state 2030: The global megatrends shaping governments. Retrieved from https://assets.kpmg.com/content/dam/kpmg/pdf/2014/02/future-state-2030-v3.pdf

Northouse, P. G. (2007). Leadership theory and practice (3rd Edition). Thousand Oaks: Sage Publications, Inc.

Peters, S. (2012). The chimp paradox: The science of minds management for success in business and in life. London: Vermilion.

Rock D., \& Ringleb, A. H. (2013). Handbook of neuroleadership. United Kingdom: CreateSpace Independent Publishing Platform.

Shahid, S. (2015). Lack of leadership. Retrieved from http://reports.weforum.org/outlook-global-agenda-2015/top-10-trendsof-2015/3-lack-of leadership/?doing wp cron=1500980728.5477719306945800781250.

Simola, S., Barling, J., Turner, N. (2012). Transformational leadership and leaders' mode of care reasoning. Journal of Business Ethics, 108, 229-237.

Sinek. S. (2015). Leaders eat last: Why some teams pull together and others don't. United Kingdom: Portfolio Penguin Random House.

Swart, T., Chisholm, K., \& dan Brown, P. (2015). Neuroscience for leadership: Harnessing the brain gain advantage. New York: Palgrave Macmillan.

Thompson, S. (2015). On claims of culture and duties of recognition in democratic states. Critical Review of International Social and Political Philosophy, 18(3), 328-348.

Yammarino, F. J., \& Bass, B. M. (1990). Transformational leadership and multiple levels of analysis. Human Relations, 43, 975-995. 

'See in Swart (2015)

ii In line with the development of theory and practice in the field, the application of neuroscience has expanded into various fields of sciences, including economics (neuroeconomics), finance (neurofinance), communication (neurocommunication), entrepreneurship (neuropreneurship), psychology (neuropsychology), marketing (neuromarketing), digital (neurodigital), medical (neurohealing), and leadership (neuroleadership).

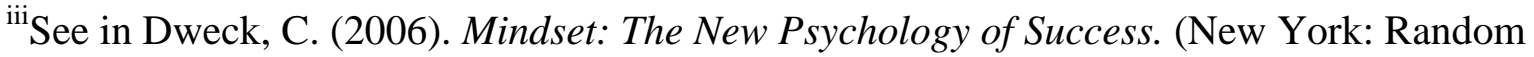
House).

iv Dopamine hormone in the brain function as messenger chemicals between nerve cells. This hormone can increase when certain activities related to happiness or triggered some types of drugs. Dopamine affects the fun of falling in love, joy, motivation, and confidence. Meanwhile, cortisol hormone or also widely known as a stress hormone, will be produced more when the body is experiencing stress, both physically and emotionally. When feeling threatened, then part of the brain will turn on the body alarm. It will then trigger the adrenal glands secrete adrenaline hormone, this coincides with the cortisol hormone.

${ }^{\mathrm{v}}$ Endorphin hormone is a natural pain killer produced by the brain, this hormone can also cause a sense of pleasure or euphoria. Increasing the amount of endorphin hormone will reduce the adverse effects of stress and pain, increase appetite, and boost the immune response.

${ }^{v i}$ The oxytocin hormone effects on behavior and emotional response is also seen in building peace, trust, and psychological stability.

vii The balance of the serotonin hormone levels will affect the mood that further contributes to the trigger or relieve depression. 